\title{
Comprehensive flood risk analysis at your fingertip through cloud-computing and standardized approach
}

\author{
Matthijs Bos ${ }^{1}$, George Peters ${ }^{1}$, Tjeerd Driessen $^{1}$, Dirk Voesenek ${ }^{1}$ and Ric Huting ${ }^{1}$ \\ ${ }^{I}$ Royal HaskoningDHV, George Hintzenweg 85, 3068 AX Rotterdam, The Netherlands
}

\begin{abstract}
Royal HaskoningDHV has been developing the Global Flood Risk Tool (GFRT). The GFRT is Royal HaskoningDHV's cloud-based platform that delivers accurate and comprehensible flood risk analysis and recommends investment proposals to reduce risk on losing lives and economic damages. The online tool is being developed inhouse by a multidisciplinary team comprising experts with geospatial, software development and flood risk expertise. The tool is written in $100 \%$ open-source software and calculates its computations on the Amazon Web Service. Clients who are currently using the tool are port authorities, private industries and international financial institutes. GFRT conducts a thorough flood risk analysis through a 5-steps approach and delivers a set of customized flood risk reduction strategies. The output is generated instantly (also for multiple scenarios), and the tool is set up in such a way that it can easily connect to, integrate or exchange with other services, tools and models. This paper shows a user case from the Port of Rotterdam, to demonstrate how the tool has been applied, how it helped the client and what were additional benefits. Furthermore, opportunities that lie ahead of the tool to continuously improve flood risk assessments and flood risk reduction strategy formulation are discussed.
\end{abstract}

\section{Introduction}

Royal HaskoningDHV has been developing the Global Flood Risk Tool (GFRT). The GFRT is Royal HaskoningDHV's cloud-based platform that delivers accurate and comprehensible flood risk analysis and recommends investment proposals to reduce risk on losing lives and economic damages.

The GFRT has been thoroughly tested and successfully applied in many international projects. These projects are at regional, district or community scale for local governments, at port scale for port authorities or for individual industrial sites for private clients. Analysis was done all over the world in: Vietnam, Myanmar, Gambia, Thailand, Canada, Netherlands, Sri Lanka and Philippines. With GFRT a thorough flood risk analysis was conducted through a 5-steps approach providing a set of customized flood risk reduction strategies formulated in close contact with the stakeholders.

This paper shows a user case from the Port of Rotterdam, to demonstrate how the tool has been applied, how it helped the client and what were additional benefits of utilizing GFRT. Furthermore, opportunities that lie ahead of the tool to continuously improve flood risk assessments and flood risk reduction strategy formulation are discussed.
USP's of the GFRT:

- Fast calculations: inundation and damage calculations within a minute instead of hours.

- Online service: Flood Risk calculations through cloud-based computing platform based on 5-steps approach.

- Visually attractive: User interface is interactive, visually attractive and understandable for non-experts to stimulate stakeholder dialogue.

- Enables decision-making: GFRT to be used for scenario modelling to support decision-making on business cases.

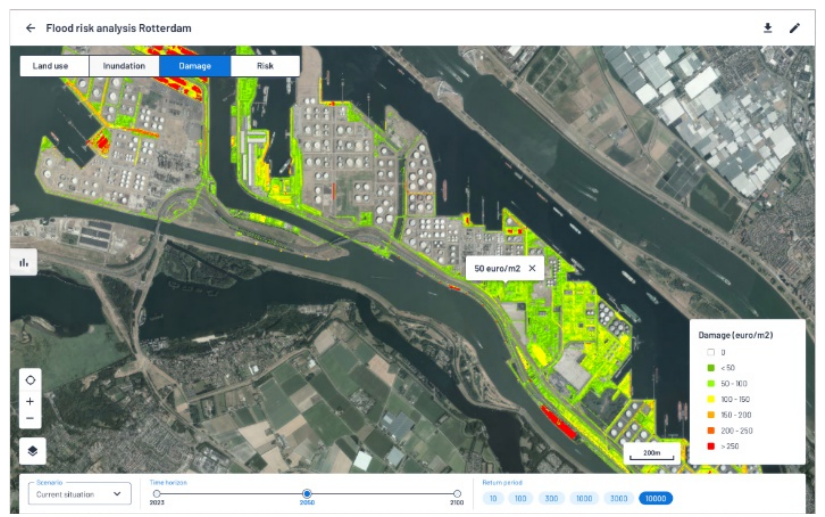

Figure 1. User interface of GFRT - damage maps climate scenario $2050(+35 \mathrm{~cm}$ SLR $)$ for 10,000 years return period 


\section{Vision on Flood resilience through key principles, multi-level safety and 5-steps approach}

\subsection{Key principles to become flood resilient}

At Royal HaskoningDHV six key principles form the basis to come to a flood resilient strategy. These key principles are presented in Figure 2, namely: transparent governance with strong policies, regulations and institution to maintain the resiliency status that is achieved; social inclusiveness through stakeholder consultation; integrated system approach (looking at both coastal, pluvial and fluvial flooding at once); design for projected future events including climate change scenarios; mix science based measures with local needs that are under planning and lastly combine efforts of private sector and government initiatives.

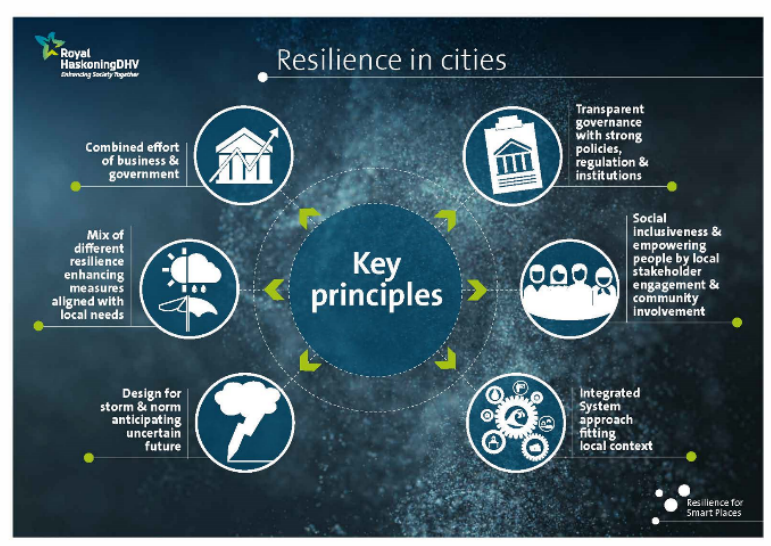

Figure 2. Key principles towards flood resilience

\subsection{Multi-level safety}

Flood resilience strategies should be well-planned and include a balanced approach for the longer, strategic perspective with a focus on low-regret measures as well as short term measures that need to be taken to protect the people and assets in the high-risk areas. Therefore, in the approach a sustainable, resiliency-focused methodology is embraced using the multi-level safety approach adopted in many regions world-wide). The proposed multi-safety level approach focusses on safety for all people in the area and reduces the potential economic damage significantly. The approach distinguishes between 3 levels of measures:

- Level 1 protective structural measures;

- Level 2 adaptive and non-structural measures;
- Level 3 emergency response measures.
Figure 3. Conceptual levels of safety. Source: Ministry of Infrastructure and Water management (I\&W) of the Netherlands (2009).

\subsection{5-steps standardized approach}

GFRT conducts a thorough flood risk assessment through a 5-steps approach and delivers a set of customized flood risk reduction strategies. All steps are interlinked which means that when any parameter is changed the whole assessment is updated.

These five steps operate independently from each other, making the tool applicable for a wider audience and facilitating the use of external data such as, detailed hydraulic models results, costs data bases, various scenarios for development and measures. Figure 4 shows the 5-steps:

1. Calculation and visualization flood hazard, providing flood maps for multiple return periods and scenarios based on existing hydraulic models, or series of water levels. Scenarios can be either related to climate change (with or without sea level rise), structural implementations (dikes vs no dikes/ dike breaching vs no dike breaching) or economic development (with land use or without future land use development).

2. Calculation and visualization of geospatial distributed economic damage, providing economic damage maps per return period and damage graph based on land uses in a given area for each scenario specified in the first step.

3. Calculation and visualization of flood risk through risk maps and risk graphs with calculated damage and annual expected and avoided damage for the different scenarios.

4. Drawing conceptual flood measures based on multilevel safety, information on investment costs for various protection levels

5. Presentation of business case by providing overview of optimum investment level with subsequent protection level for specified scenarios.

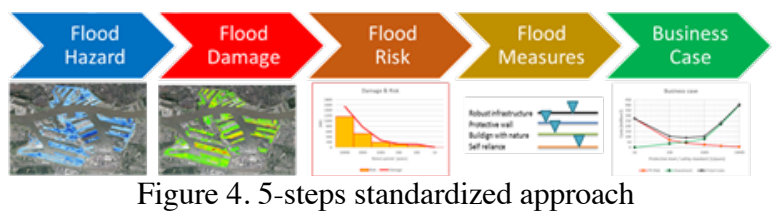

\section{Accurate \& comprehensible flood risk assessment}

The 5-steps is explained in detail in this section based on a flood risk assessment performed for the Port of Rotterdam for the Europoort by Royal HaskoningDHV (Van de Visch and Bos, 2019).

The Port of Rotterdam performed this study to get insight in the flood risk they have to adapt to when combating sea level rise. To know where and when to invest and how much budget should be reserved. This all 
with the philosophy of the port to be and remain the safest port now and in the future. For this study the risk due to economic damage, environmental impact and loss of life was assessed.

\subsection{Hazard assessment}

The hazard assessment covers the calculation and mapping of inundation depths within the project area. The user specifies for how many return periods and or scenarios this hazard assessment is required. The input data for each scenario (project boundary, elevation model and water levels) must be prepared externally from the tool.

Within the GFRT, an automated validation will be done on the raster to check if it needs to be cleaned. This means removing isolated low-lain areas - only all areas which are lower than the water level and have a connection to the original water body (e.g. sea, river, estuary) will flood. This is done by a cost allocation analysis. It checks if each inundation grid cell can reach a point from the original water body through the inundated area. If there is no connection, the inundation grid cell is deleted. If it can, the water level corresponding to the nearest water point is assigned to the inundation grid cell. This is done for every grid cell in the inundation raster.

A choice can be made between an upload of an existing inundation grid and calculation of a grid with the Flat or River method:

1. Upload: In this case the user uploads the inundation depth rasters from an existing hydraulic model for each return period within a scenario required for the risk analysis. This allows the user to manipulate inundation rasters. For example, if a surcharge for wave overtopping is to be included or if the user wants to eliminate certain areas because they are protected by structures that are neglected in the inundation modelling (see Figure 5). This can happen because the use of too coarse resolution in the grid size. The use could also think of applying option 2 or 3 .

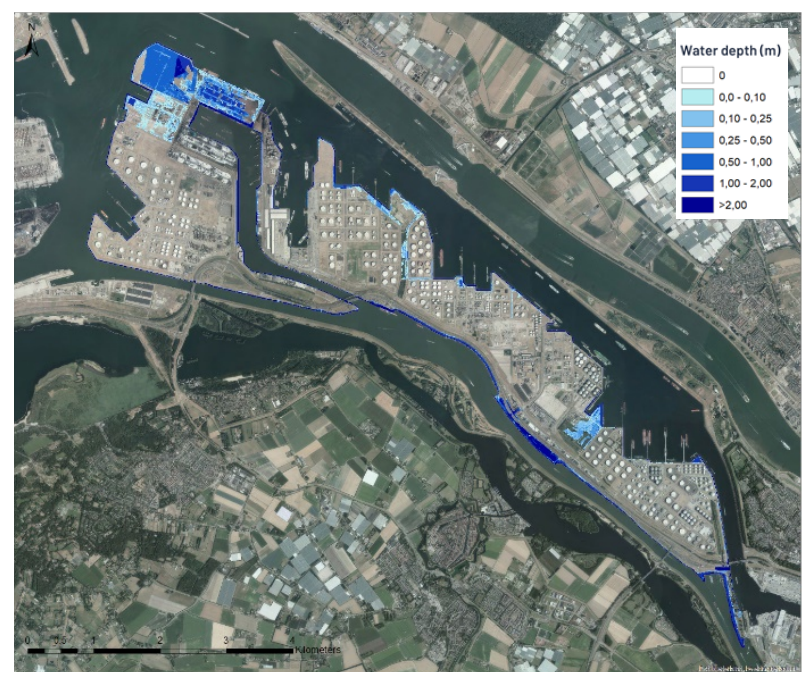

Figure 5. Upload - Inundation map of Europoort for 1,000 years return period for 2050 scenario $(+35 \mathrm{~cm}$ SLR)
2. Flat: In this case the user specifies a single water level point for each return period within a scenario. Furthermore, a DTM and polygon of the project area is required (see Figure 6).

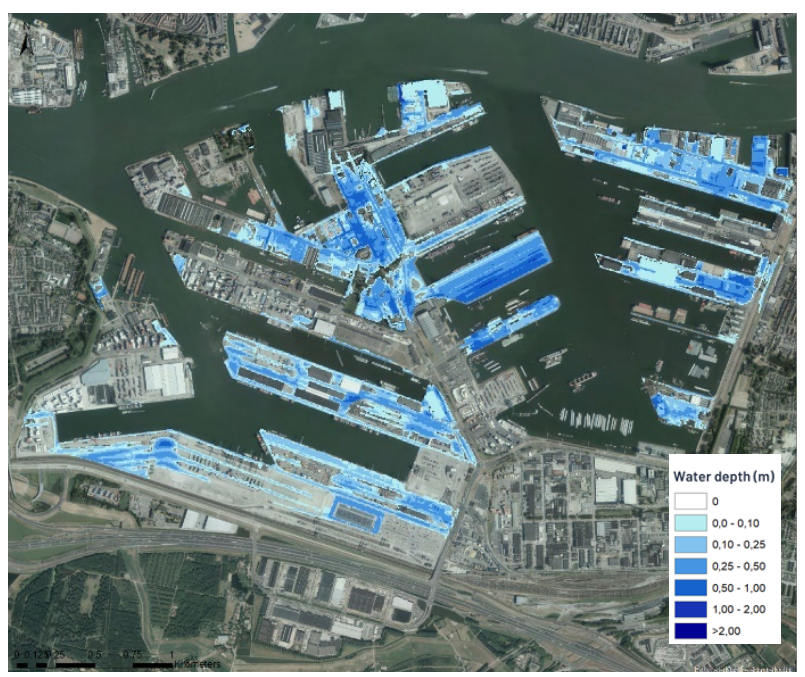

Figure 6. Flat - Inundation map of Waal Eemhaven for 1,000 years return period for 2050 scenario $(+35 \mathrm{~cm}$ SLR)

3. River: In this case the user specifies a series of water level points for each return period within a scenario. This can be either along a river stretch or within a harbour basin or estuary (Figure 7). The user can specify the river alignment to smoothen the interpolation between the provided water level points in case the amount of points is limited. Furthermore, a DTM and polygon of the project area is required.

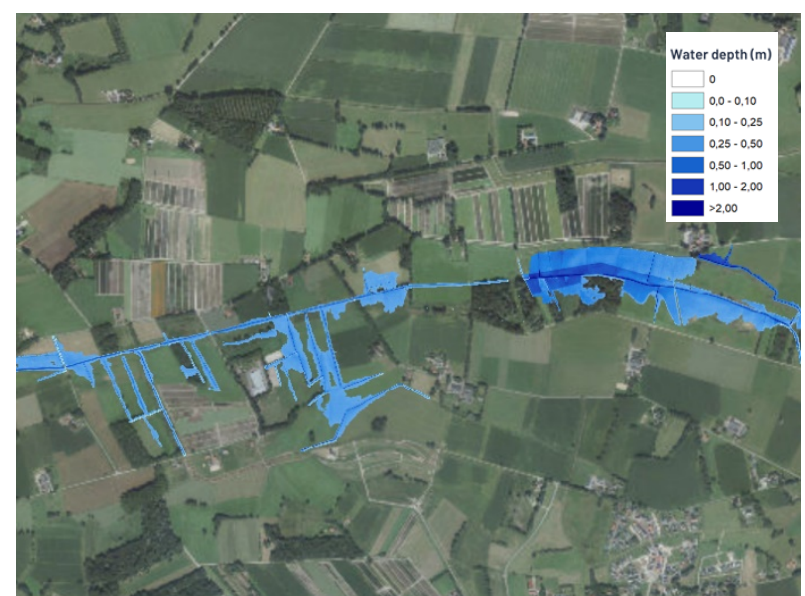

Figure 7. River - Inundation map of example river section 


\subsection{Damage assessment}

\section{Direct Damages}

Damage curves (or vulnerability curves) express the basic relation between occurring hazards by means of water depth at an asset and damage sustained as a fraction of the economic value of that asset. The assets within an area are covered by land use maps. Damage curves are generally location specific to include characterises and vulnerabilities of the project area. Damage curves from literature can be used as a starting point and can be tailormade together with stakeholder and local available data.

Most commonly used global database with damage curves and economic land use values is from the Joint Research Centre (Huizinga et al., 2017) or from Deltares (Bruijn et al., 2015). For the Port of Rotterdam the damage curves and economic land use values are obtained from a Tebodin study (Snuverink et al., 1998) and have been made project specific together with the industries in the port (see Figure 8 and Table 1). The economic land use values always need to be validated and corrected (in this case from 1998 to 2015) according the CPI over this period. The results of the damage calculation need to be calibrated against actual historic event from which damages are known.

The data required for the Land use maps in many occasions comes from the client or local stakeholders (Figure 9). If that is not available, it can be modelled for satellite imagery in combination with for instance Open Street Map and Google maps.

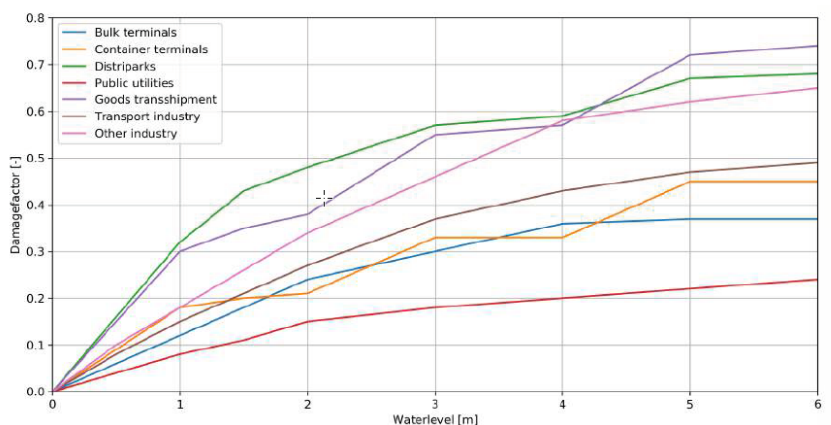

Figure 8. Damage curve for land use categories

\begin{tabular}{|l|c|}
\hline Land use category & Value [€/m2] \\
\hline Bulk terminal & 443 \\
\hline Container terminals & 696 \\
\hline Distriparks & 886 \\
\hline Public utilities & 1583 \\
\hline Good transshipment & 886 \\
\hline Transport industry & 633 \\
\hline Other industry & 633 \\
\hline
\end{tabular}

Table 1. Economic values of land use categories

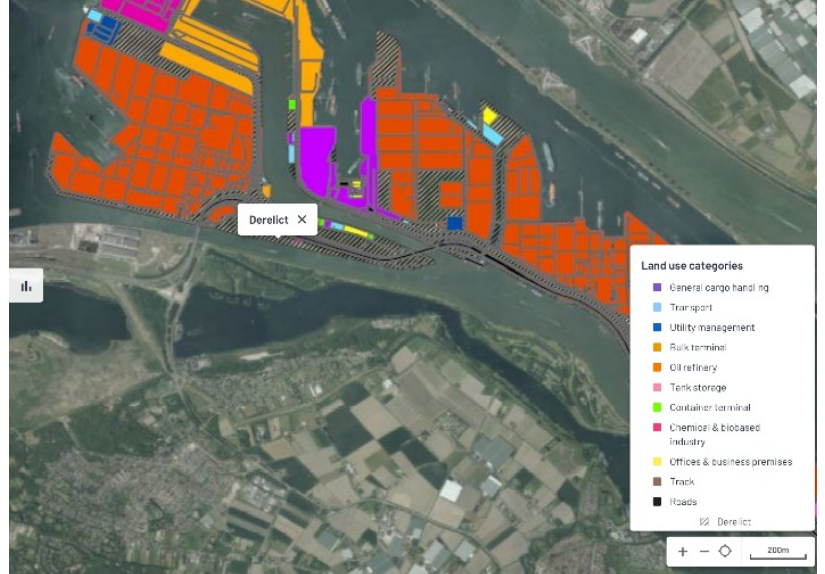

Figure 9. Land use map for port area

The direct damage output is generated instantly on geospatial rasters (also for multiple scenarios, width large extents of $20 \times 20 \mathrm{~km}$ and grid cells of $5 \mathrm{~m}$ resolution). This give the advantage that damages can be interpreted at local scale. Figure 10 shows the output of the direct damage calculation for the 1,000 and 10,000 return period for the 2050 climate scenario. From damage rasters directly can be seen which areas are most vulnerable to flooding and would most heavily be impacted in case of a severe event.
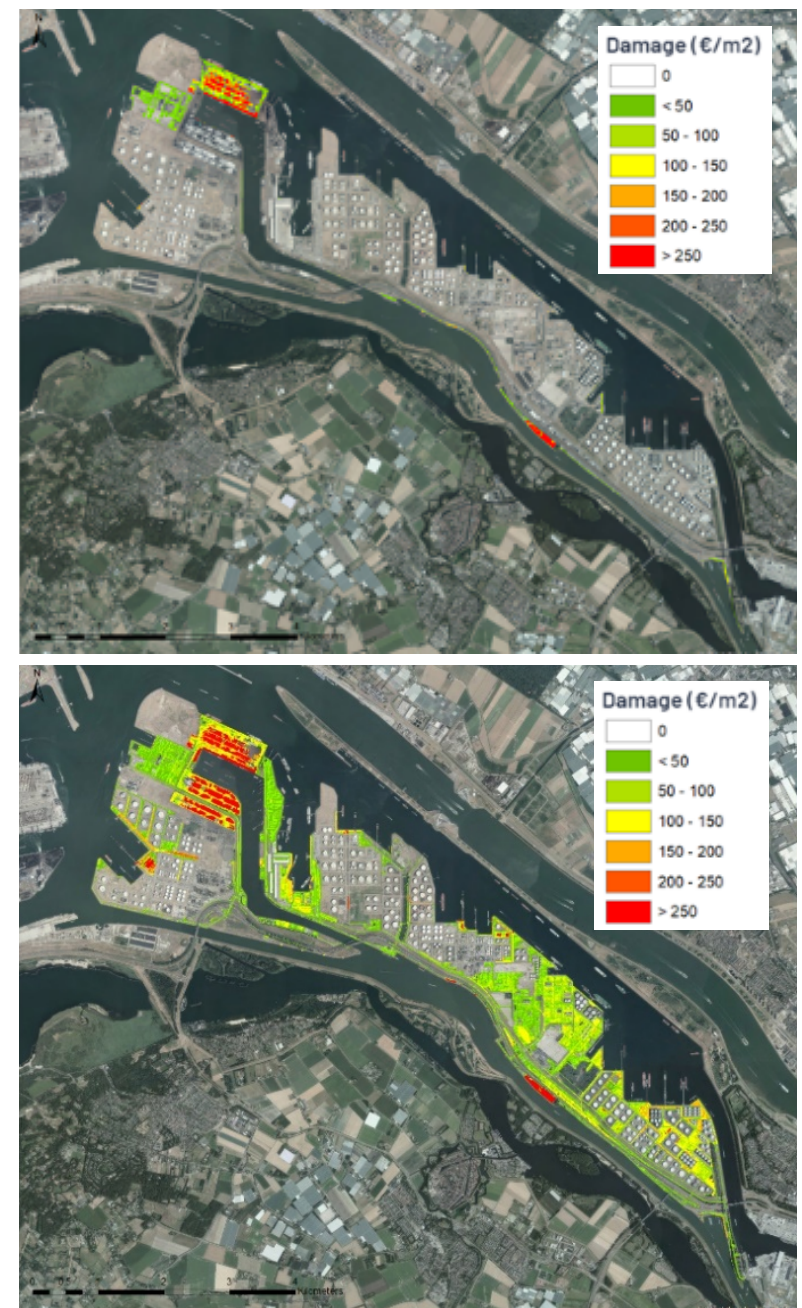

Figure 10. Damage maps climate scenario 2050 (+35cm SLR) for 1,000 years (upper) and 10,000 years (lower) return period 


\section{Indirect Damages}

Next to direct damages, indirect damages are an important part of flood and erosion damage. Indirect damage due to flooding consisting of disruption to productive activities, employment, travel and additional costs associated with flood management and flood proofing the private sector.

The indirect damages can be calculated with an input-output (ARIO) model (Hallegatte, 2008 and 2014). This was also done for the Europoort case. The input for the model was developed in close corporation with the Port of Rotterdam.

More frequently the indirect damages are calculated as a proportion of direct damages using a multiplier. While this relationship is relatively well established, the size of the multiplier differs significantly between various different studies (Table 2). It should also be noted that some of these losses are associated with extreme weather events such as typhoons rather than flooding in isolation. Nevertheless, some of the largest indirect damage multipliers are associated with flood events, indicating the possible significance of indirect economic disruption and cost due to flooding alone.

\begin{tabular}{|c|c|}
\hline Event/model & Fraction of direct damage \\
\hline Elbe floods 2002 & $5 \%$ \\
\hline UK Floods 2007 & $12 \%$ \\
\hline Hurricane Katrina 2005 & $30 \%$ \\
\hline ARIO (input-output model) & $30 \%$ \\
\hline Hurricane Sandy 2012 & $37 \%$ \\
\hline Japan Tsunami 2011 & $50 \%$ \\
\hline Typhoon Damrey 2017 & $100 \%$ \\
\hline Thailand flood 2011 & $125 \%$ \\
\hline \multicolumn{2}{|c|}{$\begin{array}{l}\text { Table 2. Indirect Damages as Fraction of Direct Damages. } \\
\text { Sources: Bruijn et al. (2015) and World Bank (2018) }\end{array}$} \\
\hline $\begin{array}{l}\text { The default indirect } \\
\text { are assumed to be } 100 \% \\
\text { has the possibility to incl } \\
\text { from parallel studies. Gi } \\
\text { the indirect damage facto } \\
\text { conducted for multiplier } \\
150 \% \text {. The output for this } \\
\text { instantly and can easily co } \\
\text { an appropriate damage fac }\end{array}$ & $\begin{array}{l}\text { lage factors due to flooding } \\
\text { rect damages. The user also } \\
\text { calculated indirect damages } \\
\text { he uncertainty surrounding } \\
\text { nsitivity analysis can easily } \\
\text { es of for example } 50 \% \text {, and } \\
\text { sitivity analysis is generated } \\
\text { red within GFRT to propose } \\
\text { to the stakeholders. }\end{array}$ \\
\hline
\end{tabular}

\subsection{Risk \& Vulnerabilities}

Risk in the GFRT is defined as the potential for loss, damage or destruction of an asset, or system, as a result of a hazard and the vulnerability to this hazard, expressed by the damage function and economic land value. Risk is defined as Probability x Consequence. The Probability is in this case the probability associated with the occurrence of the hazard. The Consequence is the damage to assets and land.
The Risk calculation and vulnerability assessment is down on the following indicators:

1. Flood direct damage modelled return periods for different scenario's;

2. Indirect damage based on multiplier or on modelled direct damage (from external input-output model);

3. Annual Expected Damage (AED): total risk for all return periods per year per protection level;

4. Annual Avoided Damage (AAD): risk up to defined protection level, e.g: 100 years protection level. This is the AED minus the protected expected damages and correspond to the benefit of implementing a measure;

5. Vulnerability assessment of sectors at risk: Critical infrastructure and assets affected for different return periods;

6. Number of Affected people per year based on population density map from the (University of Southampton, 2015);

7. Risk on losing lives due to flood;

Figure 11 shows the damage and risk outcome of the Europoort case. The red line represents the total damage results (direct + indirect damage) for the different return periods for the 2050 scenario. The orange area under the damage line represents the risk, which is the integral of the damage.

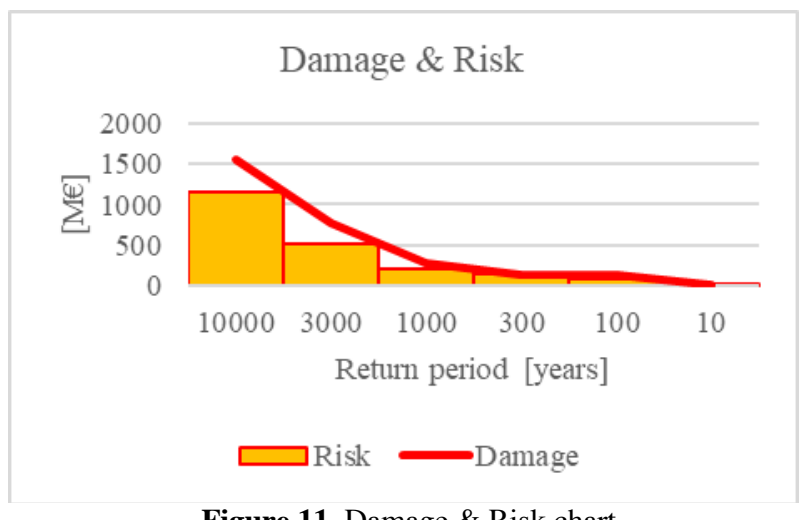

Figure 11. Damage \& Risk chart

Figure 12 shows the Annual Expected Damage (AED) and Annual Avoided Damage (AAD) for the different specified return periods. The AED is highest for the lowest protection level, visa versa the AAD is highest for the highest protection level. The protection level means to what level measures where implemented to reduce the risk. From the figure the direct effect of investing in additional safety can be seen. For every incremental step in protection level the AAD increases, while the AED decreases until there is almost no AED left for the 1:10.000 years safety standard / protection level. Figure 13 shows the relation between the AED and AAD. This figure shows that the added value of increasing your protection becomes less value for money when reaching higher protection levels. In section 3.5 an approach on advising the most optimal protection level is described. 


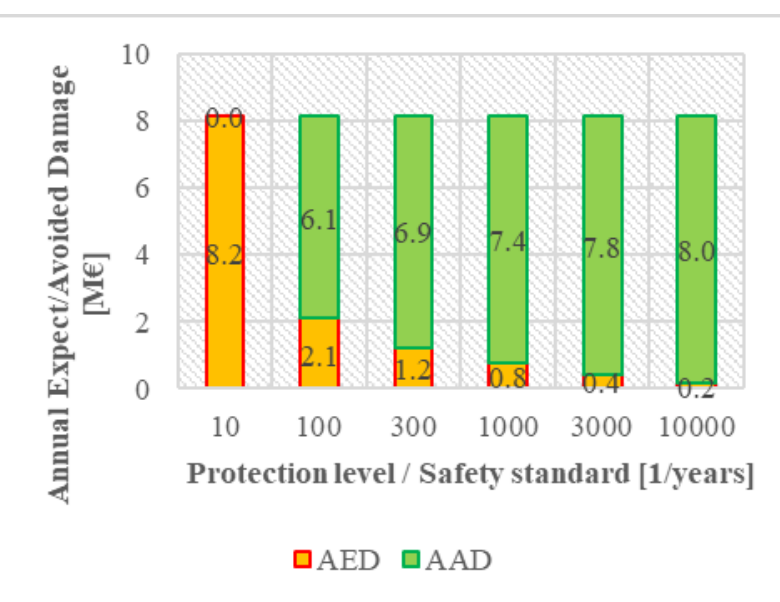

Figure 12. AED vs AAD (M€)

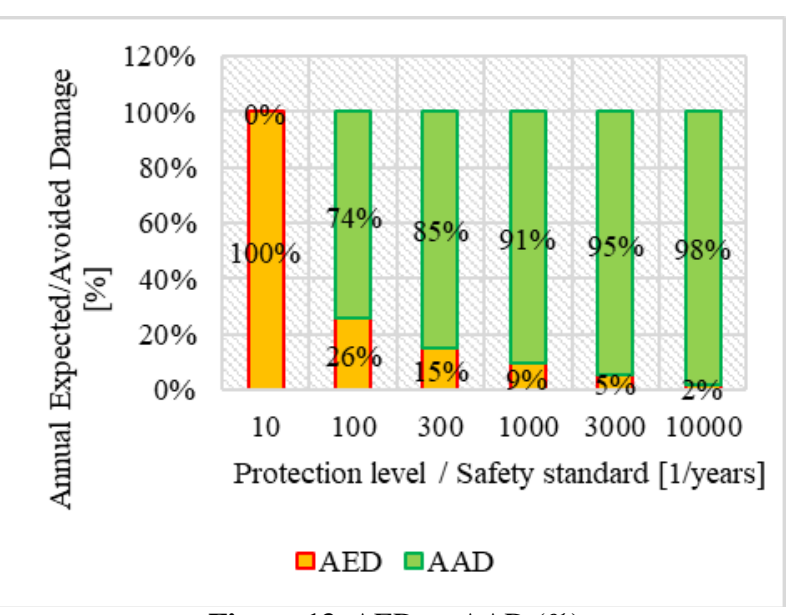

Figure 13. AED vs AAD (\%)

\subsection{Develop set of Measures}

Based on the hazard, damage and risk \& vulnerability assessment we will come up with appropriate measures based on the multi-level safety approach to reduce the impact of hazards and to mitigate the risks.

The measures can either reduce the risk by lowering the probability of a flood by increasing the protection level, or by reducing the consequences (impact) by emergency response and crisis management.

To become flood resilient, measures can be implemented. These can be a mix of grey/green/hybrid structural measures (level 1) and adaptive, non-structural (level 2) and emergency response measures (level 3), for example:

- Level 1 protective structural measures: dikes, spillways, culvert, sluices (grey) mangroves, wetlands, foreshores, nourishments, increasing conveyance by dredging and river widening (green) and storage areas, side channels and dike in dune system (hybrid)

- Level 2 adaptive and non-structural measures: raising terrains or floors, dry/wet proofing (adaptive), land use planning, relocation/ managed retreat, operation and maintenance protocols, monitoring, building codes and laws and regulations (nonstructural).
- Level 3 emergency response measures: early warning response systems, emergency response and crisis management plans (controlled shutdown, stock removal), evacuation routes and storm shelters and temporary dikes.

These measures can be combined to several strategies (short and long-term) to be further assessed through MCA and CBA. Measures can be obtained from a pre-defined Measures Toolbox (see Figure 14), gathered over time in numerous international projects in which they were found appropriate.

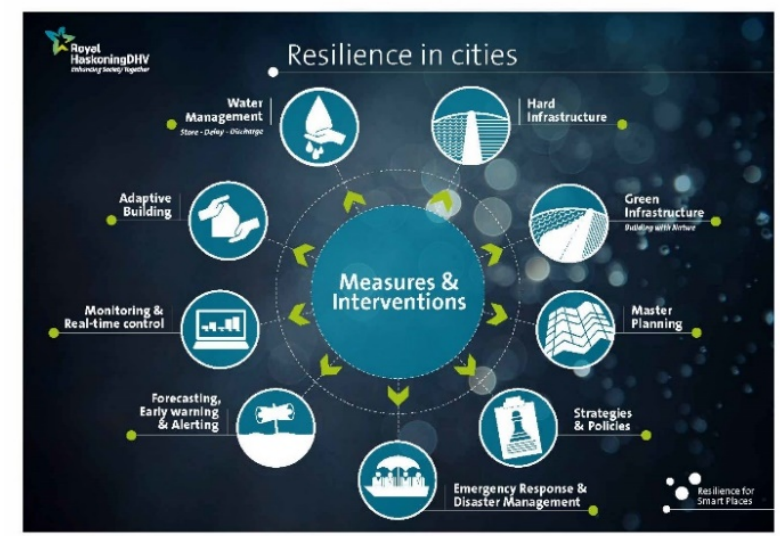

Figure 14. Toolbox of Measures \& Interventions to create flood resilience

Measures are defined at a pre-feasibility level, such as to enable to assign an indicative cost and overall investment budget. Cost are assessed for each measure based on standardized cost database. This database has a set of unit prices for measures based on reference projects (local and international), expert judgement and local conditions per country.

\subsection{Business case modelling to formulate preferred strategy}

The business case modelling addresses three topics that could initiate investing in an area:

1. define optimal protection level for investment for total project area;

2. assess the threshold for investments, when, how and how much budget is available;

3. assess what is the preferred strategy through economic assessment on defined sub areas that includes a financial cost-benefit analysis and multi-criteria analysis to include for non-tangible environmental, technical and social-economic benefits.

Input parameters for the assessment are the lifetime of measures, discount rate and economic growth factor. The lifetime varies from 30 years in middle income countries to 100 years (unlimited) for developing countries. The discount rate and economic growth rate are county specific and can be obtained from open databases. 


\section{Define optimal protection level}

This assessment is done on the total project area for the 2050 scenario. The optimal protection level is found when the incremental costs for investing in a higher protection level becomes higher than the reduction of risk obtained (Van Dantzig, 1956). The timing of investment can be found by calculating when the protection system does not meet the requirements anymore (Eijgenraam et al., 2014) Figure 15 present this economic optimization in a clear chart. It shows that an optimal protection level in this is somewhere between $1 / 300$ and 1/1,000 years protection level.

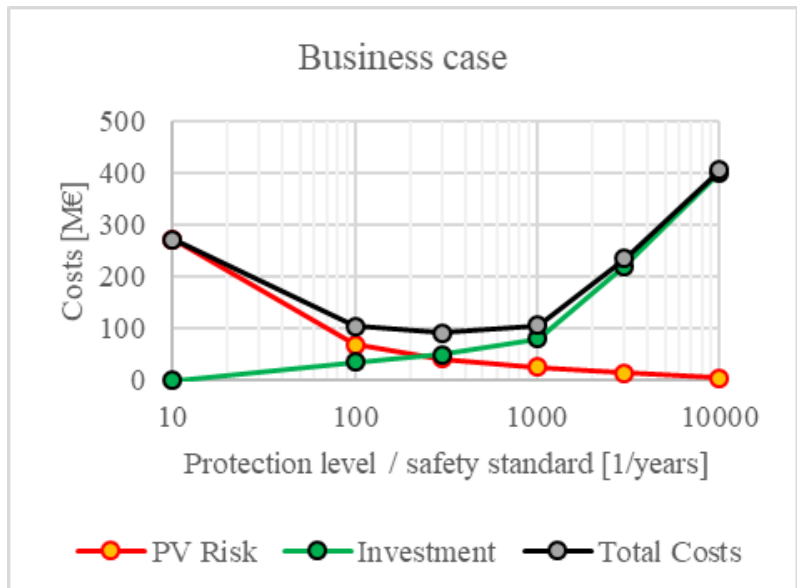

Figure 15. Economic optimization chart

Furthermore, the Net present value (NPV) of your benefits and the Benefit-cost ratio are indicator that complement the economic optimization chart. The net present value is the present value benefit - total cost (investment + present value risk). The highest NPV is the optimal case (see Figure 16).

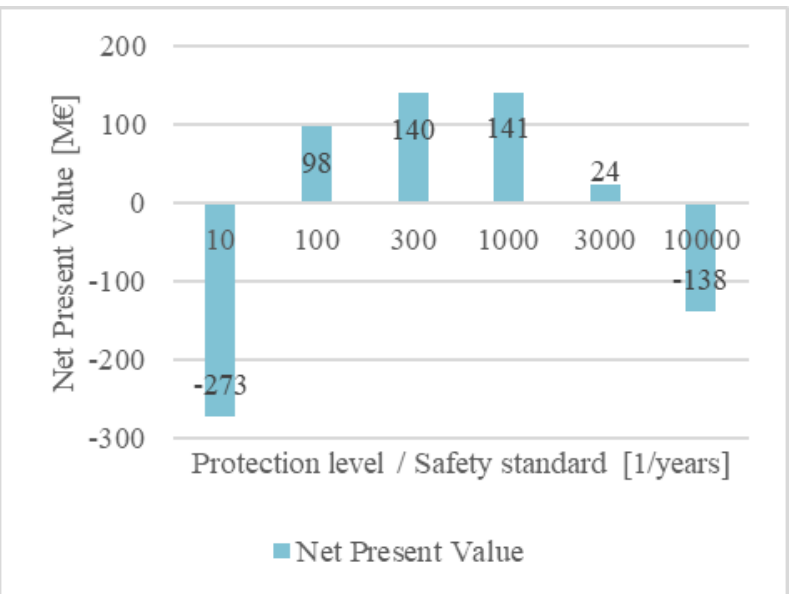

Figure 16. Net present value

The Benefit-cost ratio (BCR) is calculated by present value benefit divided by total costs (investment + present value Risk). BCR $>1$ mean a viable business case (see Figure 17).

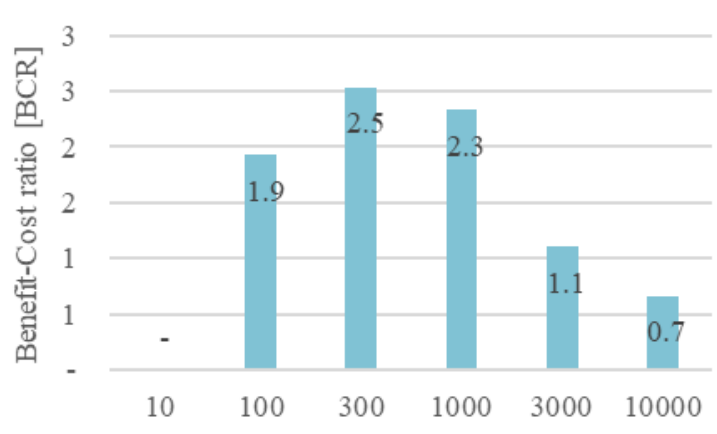

Protection level / Safety standard [1/years]

Benefit-Cost Ratio

Figure 17. Benefit-cost ratio

2. Threshold that determines when, how and how much to invest

There can be multiple reasons that determine when, how and how much can be invested. The following reasons can be assessed in GFRT:

- Timing of measure when threshold for residual risk is reached, this the approach for Europoort case: Economic risk $>400 € /$ ha/year or risk of loss of life $>10^{-5}$

- Risk matrix with identified scenario's, according to corporate risk procedures investment could be triggered;

- Percentage of AED that is required to be protected;

- Threshold of total economic damage that needs to be protected (maximum investment capacity of region or industry to respond after event);

- Protection level enforced by law (by safety norm);

- Timing of measures to have synergy with planned investments;

- Available budget to limit risk to maximum protection level.

\section{Compare strategies to come to preferred strategy}

GFRT is designed such way that scenarios (structural, climate change or economic development) and strategic options (level 1,2 or 3 measures or combinations) can be easily compared to each other because all scenarios and strategic options are modelled in a single project environment in order to find the preferred strategy. The effectiveness of the possible strategies will be modelled through an economic assessment that includes a financial cost-benefit analysis and multi-criteria analysis to include for non-tangible environmental, technical and socialeconomic benefits (see Figure 18).

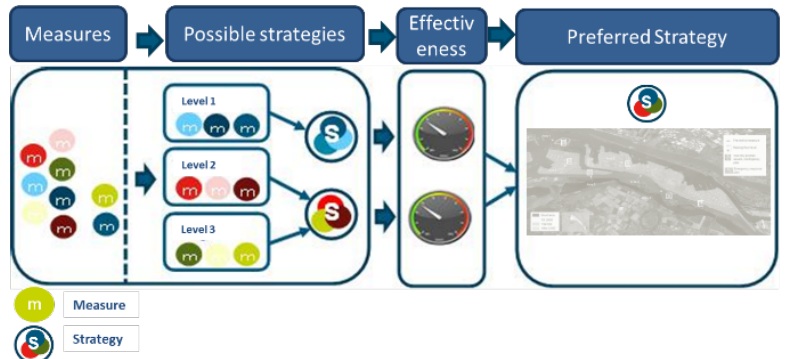

Figure 18. Approach towards preferred strategy 
The financial assessment progresses on the economic optimization assessment. This assessment is on specific sub areas that require protection. For the Europoort case, the area was divided in six sub areas, Figure 19. Measures have been defined following the multi-level safety approach for the sub areas and for the total project area. The 2050 scenario and 1/1,000 years protection level for the basis of the assessment. Each of these measures have their specific present value risk and benefit and required investment, see Table 3.

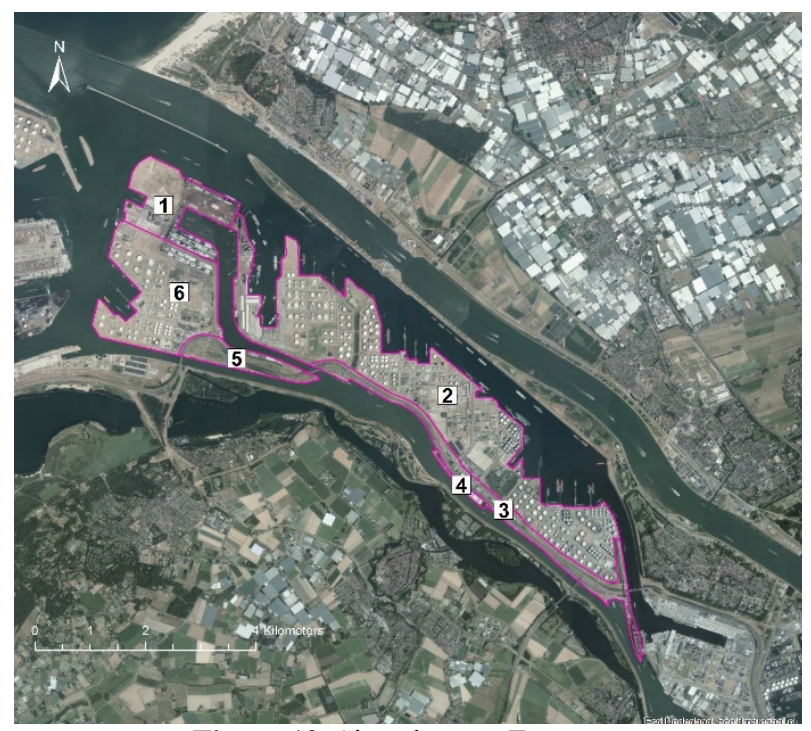

Figure 19. Six sub areas Europoort

Figure 20 and Figure 21 show the results of the Europoort case for the strategic options. The assessment clearly shows that flood defense measures for Area 1 (A1) and 4 (A4) are favourable as the NPV and BCR are positive and highest. Dry/wet proofing only is viable for Area 3 (A3), not for Area 2, 5 and 6. (A2, A5 and A6). To protect the total area with a moveable flood barrier (T1) or only doing emergency response measures does not seem to be financially viable. Emergency response measures are proposed additionally to the protective and adaptive measures.

\begin{tabular}{|l|c|c|c|}
\hline Strategic option & $\begin{array}{c}\text { PV Risk } \\
(\mathrm{M} €)\end{array}$ & $\begin{array}{c}\text { PV Benefit } \\
(\mathrm{M} €)\end{array}$ & $\begin{array}{r}\text { Investment } \\
(\mathrm{M} €)\end{array}$ \\
\hline A1 - flood defense & 8.0 & 219.0 & 6 \\
\hline A2 - dry/wet proofing & 5.0 & 6.0 & 50 \\
\hline A3 - dry/wet proofing & 1.5 & 9.4 & 6 \\
\hline A4 - flood defense & 1.0 & 30.9 & 2.4 \\
\hline A5 - dry/wet proofing & 0.07 & 0.06 & 2.5 \\
\hline A6 - dry/wet proofing & 2.0 & 2.0 & 1.3 \\
\hline T1 - flood barrier & 15.0 & 267.0 & 820 \\
\hline T2 - emergency response & 245.0 & 37.1 & 10 \\
\hline
\end{tabular}

Table 3. Measures for six sub areas and two for total area in the Europoort

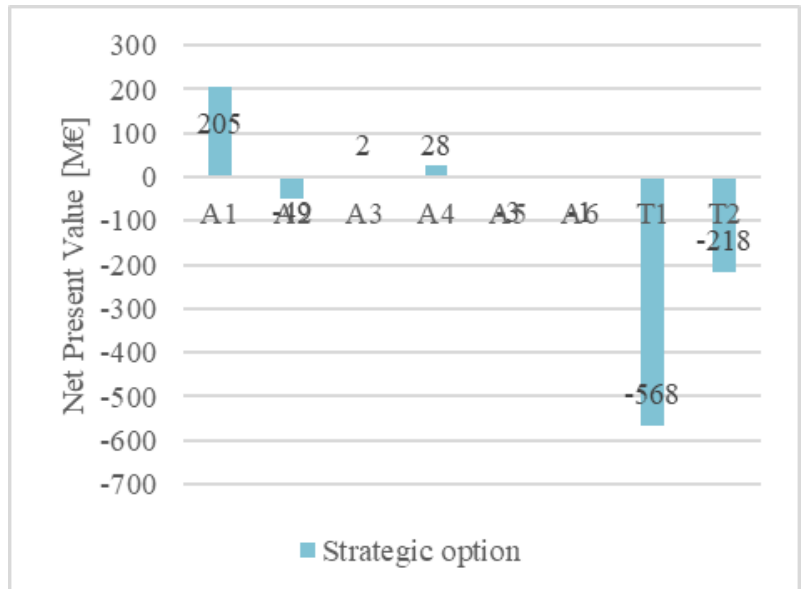

Figure 20. Net present values of strategic options

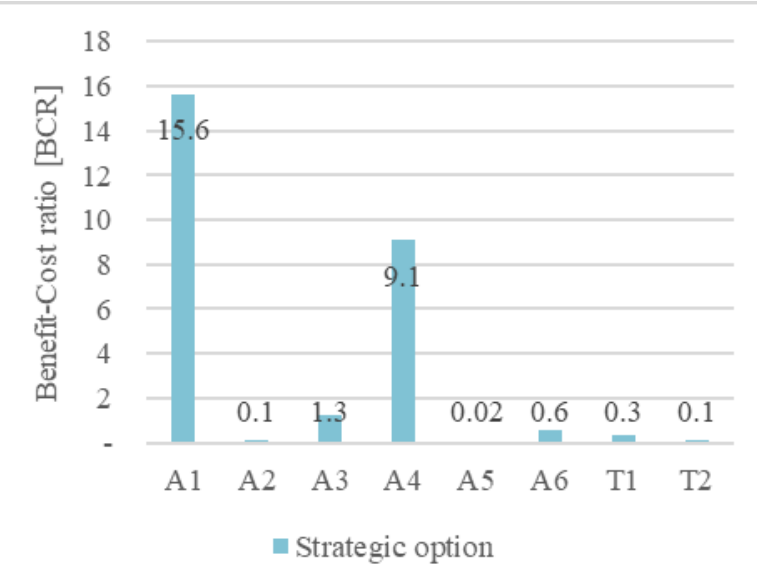

Figure 21. Benefit-cost ratio of strategic options

To complement the financial assessment a standardized approach to a Multi-Criteria Analysis is set up that can be customized for specific projects. This way the strategies can be compared based on the non-tangible benefits related to:

- technical (e.g. adaptive to climate change, effectiveness, does it require relocation, does it have stakeholder support, replicable and scalable);

- economic/planning aspects (e.g. urgency, consistent with policy and plans, does it stimulate the economy).

- socio-economic (e.g. protect people affected, reduce risk on losing lives, benefiting women or minority or vulnerable groups);

- environmental impacts (e.g. disturbance or destroys habitats) and;

The preferred strategy for the Europoort case is as follows: investment in Area 1 and 4 should be implemented as soon as possible, critical assets in Area 3 should be protected before 2050 and apart from development of an emergency response plan for the project area, additional investments in the other areas (Area 2, 5 and 6) have no priority and can wait till after 2050. Climate change scenarios have to be monitored. In case of large deviation compared to applied scenario's it was recommended to perform an update on the advised preferred strategy. 


\section{Unique selling points of GFRT, lessons learned and opportunities for the future}

The online GFRT is being developed inhouse of Royal HaskoningDHV by a multidisciplinary team comprising experts with geospatial, software development and flood risk expertise. This gives the advantage that continuous developments can be done depending new user requirement from clients and stakeholders to keep up to date with the latest innovations and techniques in the market.

\subsection{GFRT has the following USP's:}

- Fast calculations: inundation and damage calculations within a minute instead of hours

- Online service: Flood Risk calculations through cloud-based computing platform based on 5-steps approach

- Visually attractive: User interface is interactive, visually attractive and understandable for non-experts to stimulate stakeholder dialogue.

- Enables decision-making: GFRT to be used for scenario modelling to support decision-making on business cases

Fast calculations: The tool is written in $100 \%$ opensource software, e.g.: Python, GDal and GeoServer and calculates its computations on the cloud-based platform Amazon Web Service (AWS). The front end is published in Leaflet on a (C) Mapbox map. Our code is stored in Github with a separate testing and production environment. This enables us to continuously improve the tool while still applying it in our day to day projects. New features only will be deployed after successful testing.
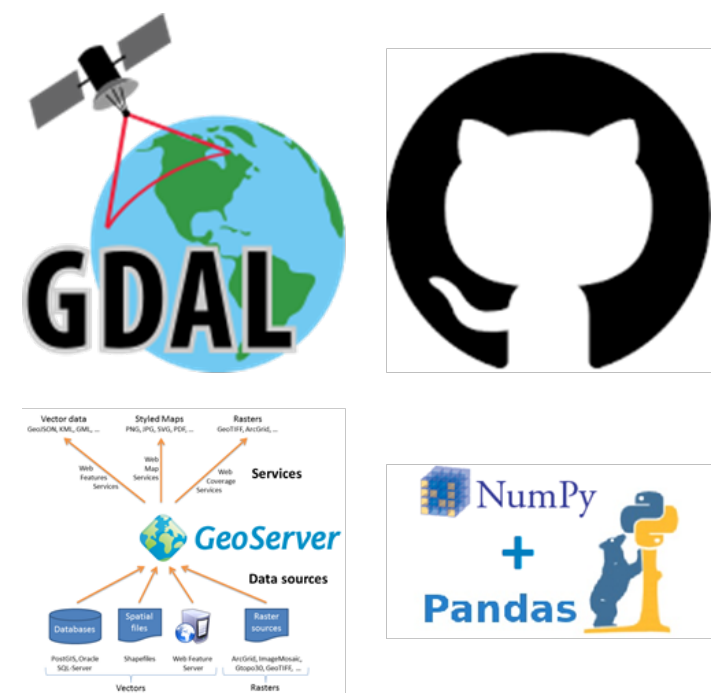

Figure 22. Set up of GFRT with open-source software packages

The tool emerged from a desktop application to a cloud-based application mainly to increase computation speed and to further automate and standardize RHDHV's approach to conducting Flood Risk Assessments worldwide. The performance went down from 5 hours for a complete set of scenarios (18 rasters of $5 \times 5 \mathrm{~km} \times 5 \mathrm{~m}$ grid size) down to 1 minute. This is achieved by applying parallel processing on AWS through lambda's. Limitations on raster extent $(400 \mathrm{~km} 2)$, resolution size ( $\max 5 \mathrm{~m}$ ) is further improved to be able to model larger extents and higher resolution. This is done through slicing the computation.

OSGEO GDAL was applied instead of ArcGIS for GEO-GIS spatial calculations to move away from licensing and verification issues that really slowed down the computations. Furthermore, issues were faces with capabilities on geo spatial (raster) visualizations.

Numpy scipy pandas have been used for the calculations, matplotlib \&ipywidgets for the visualization.

A central database is developed that stores all flood, damage and risk rasters, damage curves and land use maps from all projects environment modelled in the tool. All data can be accessed through an API to integrate or exchange with other services, tools and models.

Online service: GFRT is an online service that can be used by Royal HaskoningDHV's clients. The set-up of GFRT is designed such that it is very user friendly. Anyone who is interested in Flood resilience can work with the tool. The tool is flexible as it can create your own user cases and scenarios within. There are a number of parameters that can be tuned, all the rest is automated and standardized. This way GFRT can be easily utilized during client sessions and stakeholder meetings.

Visually attractive: The user interface of GFRT is design by User Experience Designers. The UX was designed over several stages and evolved over time to the current layout. GFRT is interactive as you can play with scenarios and intuitively experience how flood risk is modelled and how to look at it. GFRT is visually attractive, with geospatially distributed maps of flood hazard, damage and risk together with geographic indication of measures, clear charts and tables of the modelled outcome of the analysis. This way flood risk becomes understandable non-experts.

Enables informed decision-making: The fast calculations, online service and visual attractive interface enables informed decision-making for increasing flood resilience and business case modelling.

The output of the flood risk assessment is generated instantly. It is possible to do scenario modelling together with the stakeholders and play with all economic parameters. Playing with these parameters help in understanding risk and how effectively these can be responded to. This is a different from the day to day business where consultant do their assessment and bring them to client or public. Whenever new insights are brought to the table, the assessment has to be revised after these events. Now it possible to assess it together. Changing any parameters is not causing to redo the whole analysis, but the effect is seen instantly. This provides more flexibility and more options to look at. It can also be used to, finetune the inputs, without delaying the project. 
Herewith examples of inputs and parameters that could be played with to increase the understanding of the vulnerability of an area against flooding:

- Flood Hazard: Insert new climate scenarios with increased sea level rise or rainfall intensity or validate model inaccuracies with new flood scenarios.

- Damage: play with sensitivity of damage curves and economic land use values. See how sensitive certain assets or areas are against changing input parameters.

- Land use development: change land use map, for example for future planning scenarios. What happens if 50 or $80 \%$ of area transforms to urban or tourism. How would it effect the flood risk? Is it advisable to transform towards these land uses without investing in flood risk reduction measures? This is also in relation to the recommended protection level. When becomes the risk to high that an upgrade in protection level is required?

- Risk: check the robustness and sensitivity of all economic parameters, i.e.: discount rate, economic growth rate and life time of the implemented measures.

\subsection{Opportunities for the future}

Opportunities that lie ahead of GFRT are within AI (deep learning), cloud-computing power and accessibility and availability of opens-source data integrations:

- Include worldwide DTM and/or flood maps from open-source platforms as default inputs for the assessment.

- Project set up, modelling damage curves and defining the economic parameters based on AI to learn from what most commonly was used by previous users. GFRT to propose damage curves based on Land use map and in which country or area the project is located. Besides that, also proposes economic land use values. User has possibility to adjust what is proposed.

- Automated land use maps based on open-source satellite imagery with use of AI. Then connecting to API's from online platforms (e.g. Google Maps, Here and Open Street Map) to validate the processed land use maps.

- Increased cloud-computing power to further increase the calculations speed, allow for large extents and higher resolution.

\section{References}

1. De Bruijn, K., Wagenaar D., Slager K., De Bel, M. and Burzel, A. (2015). Updated and improved method for flood damage assessment SSM2015 (version 2). Deltares 1220043-003

2. Eijgenraam, C. J., Kind, J., Bak, C., Brekelmans, R., den Hartog, D., Duits, M., Roos, K., Vermeer, P., and Kuijken, W. (2014). Economically efficient flood standards for the Netherlands. INFORMS Journal on

3. Applied Analytics, 44(1):7-21.

4. Hallegatte, S. (2008). An adaptive regional inputoutput model and its application to the assessment of the economic cost of Katrina. Risk Anal., 28(3), 779799, doi:10.1111/j.1539-6924.2008.01046.x.

5. Hallegatte, S. (2014). Modeling the role of inventories and heterogeneity in the assessment of the economic costs of natural disasters. Risk Anal., 34(1), 152-167.

6. Huizinga, J., Moel, H. de, Szewczyk, W. (2017). Global flood depth-damage functions. Methodology and the database with guidelines. EUR $28552 \mathrm{EN}$. doi: 10.2760/16510:

http://publications.jrc.ec.europa.eu/repository/handle/ JRC105688

7. Snuverink, M.A.M., Van den Berg, K., Sluijs, L. en E. van Proosdij (1998). Schade bij inundatie van buitendijkse industrie (in Dutch). Tebodin, Den Haag, for Rijkswaterstaat.

8. Van Dantzig, D. (1956). Economic Decision Problems for Flood Prevention. Econometrica, 24(3):276-287.

9. Van de Visch, J. and Bos, M.F.M. (2019). Waterveiligheid Europoort - Een adaptatiestrategie voor een veilige haven - nu en in de toekomst (in Dutch). Royal HaskoningDHV, for Port of Rotterdam https://www.portofrotterdam.com/en/our-port/ourthemes/a-safe-port/water-safety/europoort

10. University of Southampton. Worldpop United Nations Spatial population data set of 2015: http://www.worldpop.org.uk/data/summary/?doi=10. 5258/SOTON/WP00297

11. World Bank (2018). Khanh Hao Provincial People's Committee, 2017 Vietnam Post Typhoon Damrey Rapid Damage and Needs Assessment. 